\title{
Carotid Body and Vagal Paragangliomas: Epidemiology, Genetics, Clinicopathological Features, Imaging, and Surgical Management
}

Sampath Chandra Prasad ${ }^{1}$ • Carlo Terenzio Paties ${ }^{2} \bullet$ Mattia Russel Pantalone $^{3} \bullet$ Renato Mariani-Costantini ${ }^{4,5}$ - Mario Sanna ${ }^{1}$

${ }^{1}$ Otology and Skull Base Unit, GruppoOtologico Piacenza, Via Antonio Emmanueli, Piacenza, Italy; ${ }^{2}$ Department of Oncology-Hematology, Service of Anatomic Pathology, Guglielmo da Saliceto Hospital, Piacenza, Italy; ${ }^{3}$ Department of Medicine - Solna, Karolinska Institutet and Department of Neurosurgery, Karolinska University Hospital, Stockholm, Sweden; ${ }^{4}$ Center of Aging Science and Translational Medicine (CeSI-MeT), Gabriele d'Annunzio University, Chieti, Italy; ${ }^{5}$ Mario Sanna Foundation (MSF), Piacenza, Italy

Author for correspondence: Renato Mariani-Costantini, Center of Aging Science and Translational Medicine (CeSI-MeT), "Gabriele d'Annunzio" University, Via Luigi Polacchi 11, 66100 Chieti, Italy. E-mail: rmc@unich.it

Doi: http://dx.doi.org/10.15586/paraganglioma.2019.ch5

Abstract: Carotid body and vagal paragangliomas, although considered indolent tumors, represent a challenge for the treating physician. This is mainly because of their peculiar localization, in close proximity with important anatomical structures. In addition, there is no chemotherapy available for these

In: Paraganglioma: A Multidisciplinary Approach. Renato Mariani-Costantini (Editor), Codon Publications, Brisbane, Australia. ISBN: 978-0-9944381-7-1; Doi: http://dx.doi.org/10.15586/ paraganglioma.2019

Copyright: The Authors.

Licence: This open access article is licenced under Creative Commons Attribution 4.0 International (CC BY 4.0). https://creativecommons.org/licenses/by-nc/4.0/ 
tumors, the role of radiation therapy is debated, and the only successful therapy is surgery. However, to achieve the best treatment goals, it is fundamental for the professional caregiver to master not only the clinical and surgical procedures but also the genetic backgrounds and the histopathological features of these tumors. We provide in this chapter a comprehensive review of the above mentioned aspects, with the aim to address the complexity of these tumors with a multidisciplinary approach.

Keywords: Carotid body paraganglioma; Digital subtraction angiography; Neuroendocrine tumors; Shamblin classification; Vagal paraganglioma.

\section{INTRODUCTION}

Carotid body paragangliomas (CBPs) and vagal paragangliomas (VPs) comprise a set of rare, slow-growing neuroendocrine tumors arising in the anterolateral aspect of the upper neck. CBPs arise from the carotid body, located at the carotid bifurcation, and VPs arise from the paraganglia along the vagus nerve, particularly the inferior nodal ganglion. VPs are less common than carotid body and tympanojugular paragangliomas. Overall, CBPs and VPs represent a surgical challenge because of their close proximity to the internal and external carotid arteries, the lower cranial nerves, and the internal jugular vein and because of their possible extension to the skull base. The clinical and surgical management may be further complicated by the fact that CBPs and VPs can show a bilateral and/or multiple presentation, especially in familial forms; metastases, on the other hand, are very uncommon (1).

In the recent decades, CBPs and VPs have received a great deal of attention from pathologists, radiologists, and surgeons, which has led to better understanding of the pathology and, hence, to better management. Various terminologies were used in the past to designate CBPs and VPs, including chemodectoma, glomus tumor, etc. Histopathologically, these tumors have been proven to originate from chromaffin-negative paragangliar tissue. Hence, the most appropriate terminology is paraganglioma (PGL).

\section{EPIDEMIOLOGY AND GENETICS}

It is estimated that head and neck PGLs (HN-PGLs) constitute 3\% of all PGLs, $0.6 \%$ of all $\mathrm{HN}$ cancers, and $0.03 \%$ of all tumors (2).CBPs, the most common form of HN-PGL, represent about $65 \%$ of all HN-PGLs and have been extensively characterised. VPs account for less than 5\% of all HN-PGLs, and, because of their rarity, their epidemiological and genetic features have not been analyzed independently from those of other HN-PGLs. However, in VPs the male to female ratio is estimated to be 1:1.87, and the mean age at diagnosis is about 45 years in familial forms and 60 years in sporadic forms. In VP patients with familial PGL, the incidence of multicentric PGLs was reported as $78 \%$ versus $23 \%$ in patients with nonfamilial PGL (3). 
The incidence rate of CBPs is overall higher in populations living at altitudes higher than 2000 meters above the sea level (4). In this regard, it has been proposed that environmental hypoxia modulates genetic predisposition to CBP (5).

CBPs can be classified into three different forms: sporadic (60\%), familial (10-50\%), and hyperplastic, that is, associated with CB hyperplasia due to chronic hypoxemia, as in subjects living at high altitudes or in patients affected with cardio-respiratory diseases (6). The latter form may occur in both familial and sporadic cases. Familial PGLs most commonly develop in the head and neck, usually in the carotid body, and up to $80 \%$ of familial paragangliomas are multifocal, compared to only 10-20\% of sporadic PGLs (7).

Patients without family history present succinate dehydrogenase (SDH) mutation only in $11 \%$ of cases, while those with familial history carry SDH mutation in $83 \%$ of cases. Patients without SDH mutation reportedly present a mean age of 50.3 years at diagnosis, while those with SDH mutation report a mean age of 38 years at diagnosis. Genetic testing is advised in case of CBPs, familial history, multicentric presentation, and young age at diagnosis (8).

PGLs, together with the related pheochromocytomas, are considered the tumors with the highest degree of hereditability in humans. Sporadic forms account for about $60 \%$ of the cases and familial (or hereditary) forms account for about $40 \%$ (9). The most frequently involved predisposition genes are those coding for the subunits of the SDH enzyme, a multiprotein complex composed of proteins encoded by the SDHA, SDHB, SDHC, and SDHD genes and by an assembly co-factor encoded by the SDHAF2 gene (10).

The hereditary paraganglioma pheochromocytoma syndrome is inherited in an autosomal dominant pattern and results from mutations in one of the four SDH genes. The SDH-related familial PGLs can be distinguished into four (10) or five (11) types: type 1, associated with SDHD, which is of particular interest here because SDHD is the gene most frequently mutated in HN-PGLs; type 2, which is rare and associated with SDHAF2 mutations; type 3, which is associated with SDHC; and type 4, which is associated with SDHB (12). Furthermore, familial PGLs can be associated with germline mutations in other genes, including RET, NF1, VHL, HIF2A, FH, TMEM127, and MAX, some of which are related to syndromic entities in which PGL may be linked to other neural crest tumors, such as multiple endocrine neoplasia (RET), von Hippel-Lindau (VHL) syndrome, neurofibromatosis type 1 (NF1), Carney-Stratakis syndrome, and the Carney triad (13).

However, the PGL-associated SDH gene variants have incomplete penetrance: in the case of SDHA only $1.7 \%$, for SDHB $22.0 \%$, and for SDHC $8.3 \%$ (14). Furthermore, engineered mice mutated in sdhb, the homolog of human SDHB, do not develop any cancer (15), which suggests that SDH gene mutations per se might not be sufficient to cause PGL.

Somatic mutations that often insist on pathways linked to PGL predisposition are clearly involved in CBP and VP, as in other PGLs. Interestingly, at the somatic level, an exome analysis performed in 52 CBPs revealed in both hereditary and sporadic cases potential tumor-associated driver mutations in genes affecting metabolism and DNA repair, including, in order of frequency, SDHD (13.5\%), IDH1 (7.7\%), ARNT (5.8\%), SDHC (5.8\%), KMT2D (5.8\%), TP53BP1 (5.8), etc. (16). 
The hyperplastic form of CBP has been mainly described in individuals living at high altitudes and in patients suffering from chronic obstructive pulmonary disease or cyanotic heart disease (6), which result in chronic exposure to low partial pressure of oxygen. This upregulates the physiological functions of the carotid body, which essentially monitors the fluctuating concentrations of oxygen, carbon dioxide, temperature, and $\mathrm{pH}$ in the arterial blood and hence regulates the cardiorespiratory centers in the medulla oblongata via the afferent branches of the glossopharyngeal nerve. Interestingly, there is an association between environmental hypoxia and gender: in fact, at sea level, the male to female CBP ratio is 1:1.4, while at high altitude it decreases to 1:8.3-a phenomenon which is still unexplained (17). Finally, hypoxia has been proposed as a modulator of SDHB/D mutations penetrance $(5,18,19)$.

\section{GROSS PATHOLOGY}

Occurring in the cervical region, where they can freely expand, CBPs and VPs come to the clinical attention as an enlarging cervical mass; at resection, their maximum diameter generally ranges from 2 to $6 \mathrm{~cm}$ (20). At gross pathological examination, these PGLs present as well-circumscribed, reddish-brown, fusiform or globular rubbery masses, often invested by a thin continuous or partial fibrous pseudo-capsule. However, their enucleation through a cleavage plane is rarely possible (21), as CBPs often encase a carotid artery and infiltrate its adventitia, while VPs infiltrate the perineuria of local nerves and may as well extend to and infiltrate the skull base. The cut surface, due to the occurrence of hemorrhages and fibrosis, is usually variegated rather than homogeneous, with yellow, tan, red, and brown areas. The specimens coming to the pathologist usually consist of quite large fragments and, notwithstanding the frequent occurrence of necrosis, hemorrhage, and iatrogenous artifacts, a definite histological diagnosis is generally easily achievable.

\section{HISTOPATHOLOGY}

The microscopic morphology of CBPs and VPs is comparable to that of other HN-PGLs, with subtle differences concerning features related to the generally larger tumor size, allowed by the specific site of origin, which permits relatively free expansion. These features include well-circumscribed profile, often with evidence of a fibrous pseudocapsule (Figure 1A), rarity of bone infiltration, frequent occurrence of extensive areas of fibrosis, presence of myelinated fibers or ganglionic structures peripheral to the tumor, and, lastly, size of the tumor cells, which, in our experience, tends to be larger than in tympanojugular PGLs.

CBPs and VPs show the characteristic "zellballen" pattern, that is, a reticular network of interlacing neuroepithelial sheets of varying thicknesses, separated by a rich microvascular bed (Figure 1B). In the microscopic section plane, this "zellballen" pattern takes the appearance of roundish or elongated oval clusters of cells. The thickness of these clusters varies from about 20 microns 

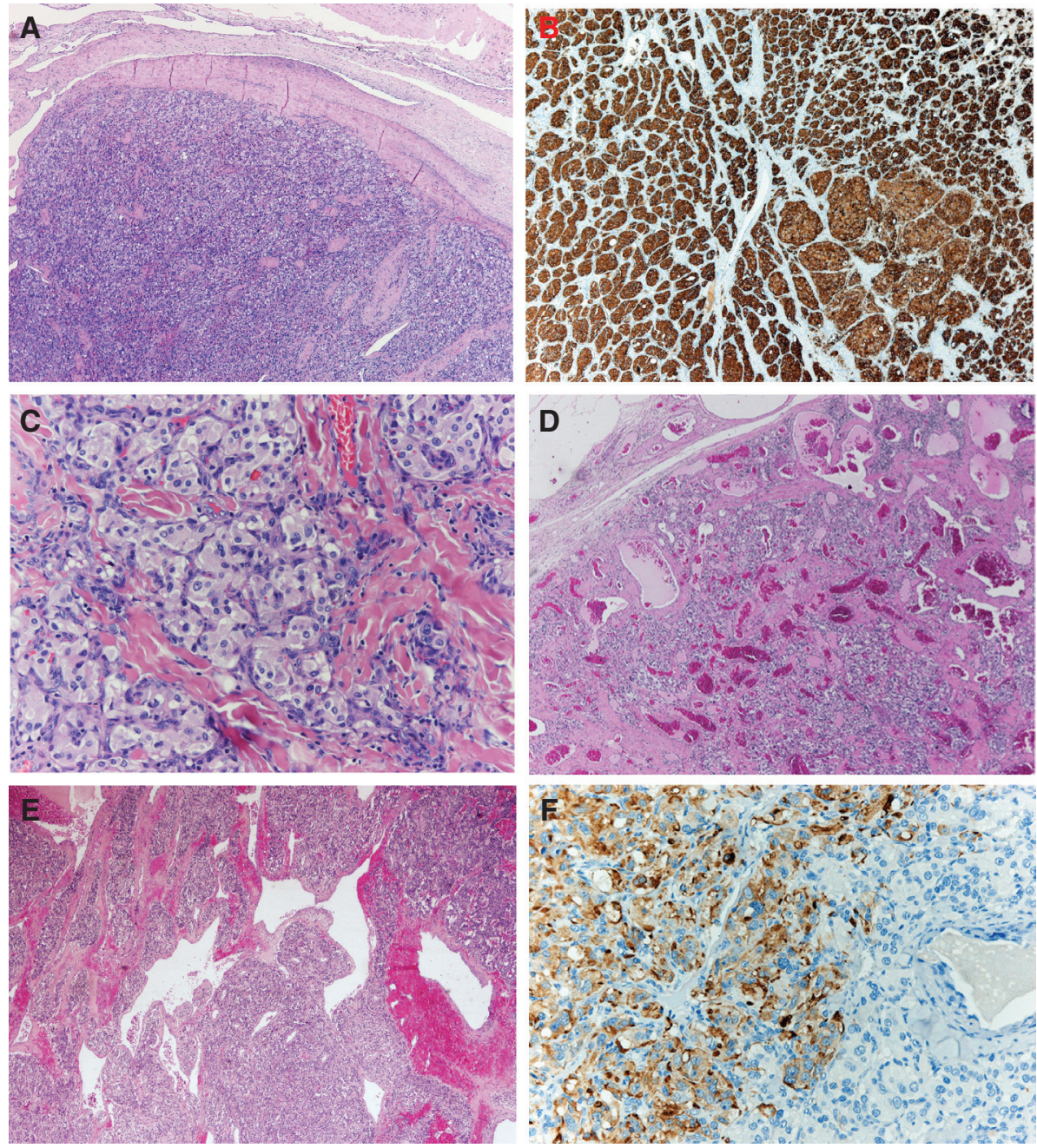

Figure 1 Histological patterns of vagal and carotid body paragangliomas. (A) Vagal

paraganglioma with well-formed pseudocapsule (HE, 40x). (B) Carotid body paraganglioma:

the meshwork of chief cells is highlighted by synaptophysin immunostaining (40x).

(C) Carotid body paraganglioma: sclerotic septa and large chief cells with oncocytic appearance (HE, 200x). (D-E) Hemangiopericytomatous patterns in carotid body

paragangliomas (HE, 40x). (F) Carotid body paraganglioma: wide variability of chromogranin A immunostaining of chief cell.(200x).

(approximately two neuroepithelial cells) up to several hundred microns, being highly variable, even within the same tumor. In our case series, a thin generally incomplete pseudo-capsule was nearly constantly observed (Figure 1A), as well as fibrosis, in the form of irregular septa between zellballens or of large sclerotic areas (Figure 1C). The extension of the fibrotic areas may vary from 5 to $90 \%$ of the tumor section surface. Ectatic, irregularly angulated, or arciform blood 
vessels are frequently observed, in association with both sclerotic areas and with florid tumor parenchyma. In a few cases, the aberrant vascular network is so prominent that it gives a "hemangioperycitomatous" pattern to the tumor (Figure 1D, 1E). Focal hemorrhage and necrosis are common, both as a spontaneous event and as a consequence of preoperative embolization. Other iatrogenous artifacts, mainly thermal and electrosurgery-related, are present in nearly all cases.

Cytologically, the zellballens contain a main population of "chief" (type 1) or neuroepithelial cells, and a minor population of "sustentacular" (type 2) cells, the latter mainly at the zellballen's periphery. Chief cells are quite large, epithelioid, and sometimes fusiform, with extensive, finely granular, and eosinophilic cytoplasm, but can also be amphophylic or clear or even vacuolated. The chief cells, identified by their immunoreactivity for chromogranin, synaptophysin (Figure 1B, 1F), NSE, and other neuroendocrine markers, contain neurosecretory granules, visible by electron microscopy and absent in sustentacular cells. In our experience, synaptophysin, a marker of the envelop of these granules, is excellent in defining the tumor structure, while chromogranin in most cases gives nonhomogeneous results, with variable immunostaining from area to area and frequent occurrence of completely negative areas. Vimentin, a mesenchymal marker, results always positive in all cell types, both vascular and neural, with variable staining intensity.

In our experience, the size of the chief (neuroepithelial) cells of CBPs and VPs ranges from 9 to 36 microns. The nuclei appear round or oval, with "salt and pepper" granular chromatin, without evident nucleoli. As in other neuroendocrine tumors, there are often isolated larger, sometimes frankly "monster" cells with giant, irregular, lobulated, and hyperchromatic nuclei, often containing vacuolar pseudoinclusions (Figure 2A). The cause of this phenomenon has not been clarified, but it does not seem to be related to malignant behavior (21). Rarely the chief cells can assume a fusiform shape, giving rise to a pseudosarcomatous pattern (21) (Figure 2B). Overall, the sustentacular cells account for only $1-5 \%$ of the tumor cells (21). Of supposedly Schwannian origin, these cells, characterized by an elongated, endothelial-like, or quasi-stellated shape with long, subtle cytoplasmic processes, surround chief cells aggregates and are brightly highlighted by S-100 immunostaining (Figure 2C, 2D). Their number varies even within each single tumor (in our experience, from 15 to 60 per high-power microscopic field) and seems to be inversely related to the thickness of the zellballen (in areas with thin zellballens, the number of sustentacular cells tends to be higher). We believe that small zellballen size may reflect regenerative phenomena after tissue injury. In fact, when the zellballens are very reduced in size, the chief/sustentacular cell ratio may decrease to $1 / 2$ in the section surface. Variability in sustentacular cell number seems to be greater in VPs compared to CBPs. In most cases ( $>60 \%)$, the proliferative index, as investigated using the Mibl antibody, is low $(\leq 1 \%)$; in the remaining cases, it may range from 2 to $10 \%$. Only occasionally, and particularly near sclerotic and/or necrotic areas, there is evidence of a high proliferative index $(\geq 10 \%)$. Chronic inflammatory infiltrates are usually absent, except occasionally and focally, next to areas of embolization (21). In a few VPs we observed peripheral infiltration of troncular or ganglionar neural structures, but we never found bone infiltration or evidence of direct vascular invasion. 

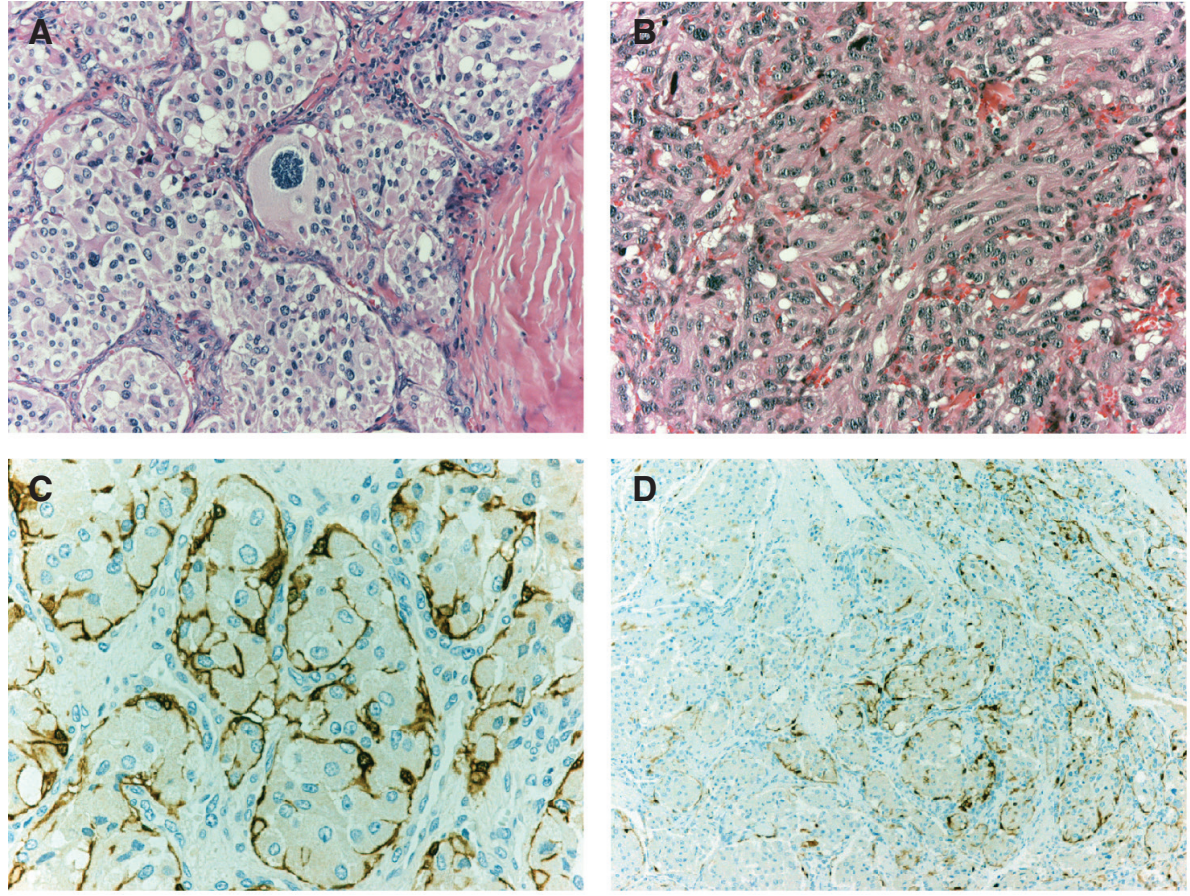

Figure 2 Atypical patterns and sustentacular cells in carotid body and vagal paragangliomas. (A) Atypical monster cell in carotid body paraganglioma (HE, 200x). (B) Carotid body paraganglioma with a pseudosarcomatous pattern (HE, 200x). (C) Carotid body paraganglioma with dendritic processes of sustentacular cells highlighted by immunostaining with antibody to S-100 (400x). (D) Carotid body paraganglioma showing dishomogeneous distribution of the sustentacular cells, immunostained with anti-S-100 (100x).

\section{DIFFERENTIAL HISTOPATHOLOGICAL DIAGNOSIS}

Imaging data are often resolutive in diagnosing CBPs and VPs. However, histopathological analysis should always rule out other tumors with similar morphology that may occur in the cervical region. These include lymph node metastases of neuroendocrine carcinomas, anaplastic carcinomas, melanomas, or renal cell carcinomas, as well as medullary carcinoma of the thyroid and other thyroid and salivary tumors with oncocytic appearance, which can mimic chief cell morphology. In this regard, immunohistochemistry for keratins and S-100 is quickly resolutive.

\section{METASTATIC BEHAVIOR}

The incidence of metastases in HN-PGLs as a whole is lower than 5\% (22) and, among all HN-PGLs, CBPs have the lowest risk of metastasis $(6,23)$. Large series of treated patients with long follow-up indicate a $2 \%$ rate of malignancy 
in CBPs $(21,24,25)$. In the smaller group of VPs, the reported frequency of metastasis varies between 7 and $10.6 \%(20,21,26)$. Nevertheless, the current opinion is that all PGLs should be regarded as malignant, that is, potentially able to metastasize, although such potential is usually very low $(22,27)$. The real problem is that of stratifying the metastatic potential according to predefinable clinical or pathological indicators. In this regard, variable criteria have been proposed, but reliable histological parameters are not available at present. Features such as cell "atypia," infiltrative profile of the tumor edge, bone invasion, or infiltration of vascular and neural structures (surely detrimental to the patient) are unreliable in predicting a metastatic behavior. Even proliferative activity does not help. Nevertheless, it is suggested that proliferative activity data based on Ki-67 immunohistochemistry should be provided in the pathological report (22).

\section{CORRELATIONS BETWEEN GENETIC AND PATHOLOGICAL FEATURES}

An integration between histopathological and genetic data is the key for the better management of a PGL patient. In particular, mutations in the SDH genes are among the most relevant in defining tumor behavior and are present in sporadic and familial cases (10). Mutations in these genes define four $(10,28)$ or five (11) PGL syndromes. PGL1 syndrome, associated with mutations in SDHD, is the most frequent in HNPGLs, particularly in CBPs (12), but CBP patients often present also other HN-PGLs and/or phaeochromocytoma and/or sympathetic trunk PGLs. Regardless of multiple presentation, the PGLl syndrome confers a low risk of metastasis. In contrast, the PGL 4 syndrome, due to constitutional mutations in SDHB, is generally associated with single HN-PGLs, but implies a high risk of metastasis (30-50\%) $(12,23,28,29,30,31)$. In this regard, a recent study of 54 patients carrying SDHB germline mutations, with a total number of 62 HN-PGLs, revealed the presence of multiple tumors in $15 \%$ of the cases, phaeochromocytoma in 2\%, metastasis in 6\%, and additional non-paraganglionic tumors in 6\% (32). The non-paraganglionic tumors are of particular relevance, as they include aggressive cancers, such as renal clear cell carcinoma and gastrointestinal stromal tumors (GISTs), as well as pituitary tumors $(32,33)$. These data emphasize the importance of detecting SDHB mutations in all HN-PGLs, as they are potential drivers of metastasis, which entails more stringent clinical follow-up.

Importantly, mutations in any of the SDH complex genes (SDHA, SDHAF2, $S D H C$, and SDHD) lead to loss of immunohistochemical expression of the SDHB protein, generally limited to chief PGL cells (32-34). Thus immunohistochemistry provides a clear indication for SDH genes testing (32). In our CBP and VP series, SDHB immunostaining resulted positive in all the paraganglioma cell types - in only 6 (4 CBPs and 2 VPs) of 21 cases, with a mild/moderate intensity of staining-and negative, only in the PGL chief cells, in the remaining 15 cases (Figure 3A, 3B). SDHA was strongly positive in all but one of the tested cases; this case was also negative for SDHB (Figure 3C, 3D). 

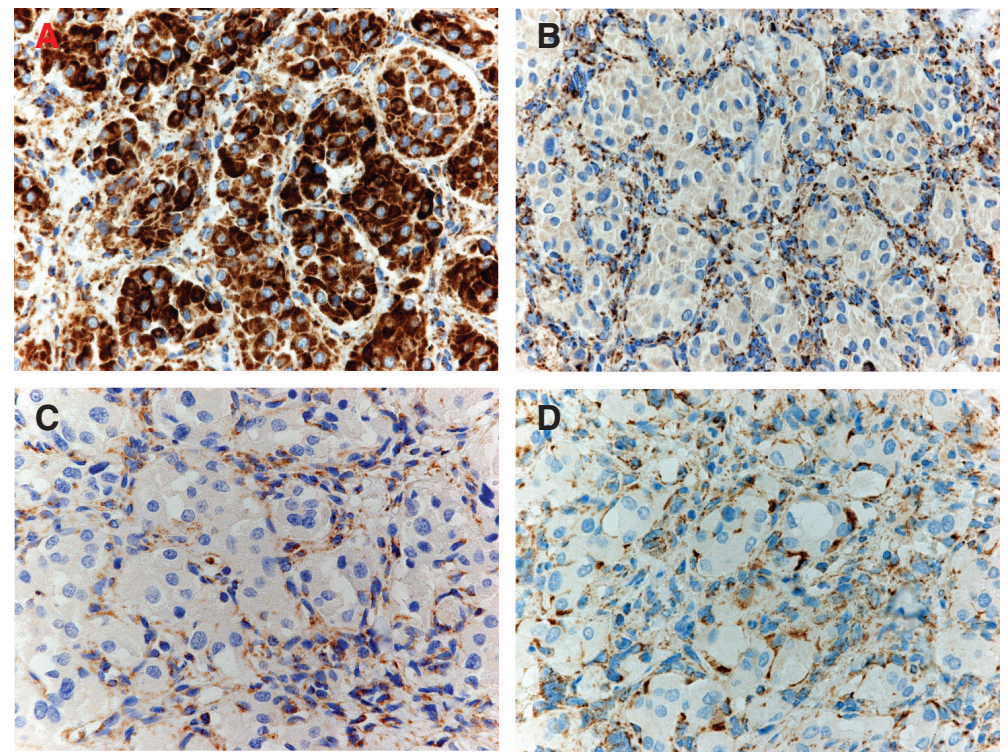

Figure 3 SDH immunostaining in vagal and carotid body paragangliomas. (A, B) Vagal paraganglioma: marked immunoreactivity for SDHA in all cell types (A) and no immunoreactivity of chief cells for SDHB (B) (400x). (C) Carotid body paraganglioma: faint staining for SDHB of sustentacular and endothelial cells, with negativity of chief cells (400x). (D) Carotid body paraganglioma: moderate staining for SDHA of sustentacular and endothelial cells, with negativity of chief cells (400x).

\section{CLINICAL FEATURES}

Both CBPs and VPs are invasive but indolent tumors. Jansen et al. (35) determined that the average growth rate of CBPs was $0.83 \mathrm{~mm}$ per year, about the same as that of other HN-PGLs. In obese patients, these tumors may go unnoticed and thereby present in advanced stages. Both set of tumors are characteristically diagnosed by their pulsatile nature and their limited mobility in their supero-inferior axis when compared to the lateral axis (Fontaine's sign) (36). They are only rarely associated with catecholamine hypersecretion and, hence, urinary catecholamine screening is often performed only in the presence of symptoms like tachycardia and/or hypertension or in case of a family history of paraganglioma. Preoperative cranial nerve paralysis is a feature of advanced lesions. Medially growing tumors may cause swelling of the oropharynx, leading to hoarseness, dysphagia, or foreign body sensation that are symptoms of the compression of cranial nerves IX, X, and XII. Furthermore, these tumors can also reach the skull base and extend intracranially $(37,38)$. Involvement of the sympathetic chain can lead to symptoms characteristic of Horner's syndrome $(39,40)$.

As mentioned earlier, VPs usually originate from the inferior vagal ganglion, also called the nodose ganglion. When they arise from the middle and superior 
ganglia, the jugular foramen, and, possibly, the atlas, may be involved. Intracranial extension associated with the cervical component gives rise to a dumbbell-shaped tumor (41).

\section{DIAGNOSTIC INVESTIGATIONS}

Neuroradiological imaging methods play a pivotal role in the diagnosis and surgical planning of CBPs and VPs. Contrast CT and MRI are complementary and are the investigations of choice, since they are able to identify the anatomical location and vascularity of these tumors. They help to differentiate PGL from other prestyloid or poststyloid tumors and from tumors that originate from the deep lobe of the parotid. They also provide vital information on potential intracranial and/or intradural spread. Specific imaging characteristics, like salt-andpepper appearance in contrast MRI, are crucial to differentiate CBPs from other tumors of the parapharyngeal space (PPS) and dictate the need for further workup, as well as choice of surgical approach (42). CT is indicated for tumors invading the skull base, to better delineate the details of the bony erosion and the extension. MRI is indicated in most cases and is complementary to CT. It will be evident radiologically that VPs are located behind the internal carotid artery (ICA), unlike CBPs, which are found at the carotid bifurcation. VPs will be characteristically found to displace both the internal and external carotid arteries anteriorly, while the internal jugular vein is compressed and displaced posteriorly (43). Digital subtraction angiography is the gold standard to study ICA infiltration, which will be seen as stenosis of the arterial lumen. It is also useful to detect the feeding vessels supplying the tumor, to check the collateral circulation through the circle of Willis and to determine the status of the venous drainage of the brain (44). It is usually performed $24-48 \mathrm{~h}$ before surgery to enable embolization of the feeding vessels. CBPs and VPs are also studied with functional imaging techniques, such as 18F-fluorodihydroxiphenylalanine (18-F-FDOPA), positron emission computed tomography (PET/TC), 18F-fluorodopamine (18F-FDA) PET/TC, or 123I-metaiodobenzylguanidine (123I-MIBG). Positron emission tomography (PET) is now being used successfully for these tumors, which express large numbers of somatostatin receptors and can be helpful in the detection of metastatic disease (37).

\section{CLINICAL CLASSIFICATION OF CBPS}

The classification proposed by Shamblin (45) has been widely accepted. However, this classification has its limitations. To truly assess a tumor, a clinical classification that helps in surgical planning and predicting outcomes is desirable, and this is where the Shamblin classification is found lacking. In fact, the Shamblin classification is essentially an anatomical and radiological classification that subdivides CBPs based on the encirclement of the internal and external carotid arteries. However, the involvement of the external carotid artery and its excision, if required, do not lead to any significant morbidity. 
Shamblin's classification also does not predict true arterial infiltration and thereby preoperative intra-arterial management. Luna-Ortiz et al. (46) rightly pointed out that small tumors (Shamblin type I) might also infiltrate the carotid arteries, thereby making excision difficult. These authors proposed a further distinction of Shamblin type III into types IIIa and IIIb, wherein small tumors infiltrating the carotid are included under type IIIb. In an attempt to make the classification more predictive, Arya et al. (47) described Shamblin types I, II, and III tumors according to the radiological degree of involvement of the ICA as $\leq 180^{\circ},>180^{\circ}$ but $<270^{\circ}$, and $\geq 270^{\circ}$, respectively. However, this is at best an extension of the existing Shamblin classification and does not accord any additional benefit in terms of surgical management or prediction of outcome. The vertical growth of CBPs poses a specific surgical challenge when these tumors reach the infratemporal fossa (skull base) and involve the carotid canal or the jugular foramen, and also this is not addressed by the Shamblin classification. Considering this, we propose a modification to the Shamblin classification, as shown in Figure 4, which allows complete and systematic assessment of CBPs and the surgical planning thereafter. This classification takes into account the involvement of the ICA and the application of intra-arterial stenting according to the infiltration of the artery. It also takes into account the compartmentalization of the PPS into upper, middle, and lower compartments and the extent of tumor spread accordingly. The choice of surgical approach is determined by the extent of the spread according to these compartments.

\section{EMBOLIZATION}

As in the case of other PGLs, also in the case of CBPs and VPs preoperative embolization is supported by the fact that these are highly vascularized tumors. However, while some authors advocate preoperative embolization $(38,41)$, others do not $(48,49)$. In our practical experience, tumor embolization usually facilitates gross total tumor removal, minimizes intraoperative bleeding, and decreases the incidence of cranial nerve paralysis (50). The decision for embolization depends on tumor size and angiographic findings. In small tumors with a minimal blood supply, embolization is not performed. When the size ranges between 3 and $5 \mathrm{~cm}$ in diameter, embolization of external carotid artery branches, such as the ascending pharyngeal and the occipital arteries, is performed.

\section{SURGICAL TREATMENT}

The factors to be considered in the treatment of CBPs and VPs are age, lower cranial nerve paralysis, internal carotid artery involvement, and multicentricity. As a general rule, in young patients, a total tumor resection must be attempted, as they usually tolerate the loss of lower cranial nerve function; on the contrary, a waitand-scan policy or radiotherapy may be adopted for older patients or patients who are not fit for surgery. 


\begin{tabular}{|c|c|c|c|c|}
\hline Tumor type & Description & Extent & Intra-arterial stenting & Approach \\
\hline Class I & $\begin{array}{l}\text { Tumor is limited to the carotid bifurcation (lower compartment of the } \\
\text { parapharyngeal space) } \\
\text { Tumors with an angle of contact of }<90 \text { degrees with the wall of the intemal, } \\
\text { extemal or the common cartid }\end{array}$ & & Not indicated & $\begin{array}{l}\text { Transcervical } \\
\text { approach }\end{array}$ \\
\hline Class II & $\begin{array}{l}\text { Tumor is limited to the middle compartment of the parapharyngeal space } \\
\text { Tumors with an angle of contact of }>90 \text { degrees but }<180 \text { degrees with the } \\
\text { wall of the intemal, extemal or the common carotid }\end{array}$ & & Not Indicated & $\begin{array}{l}\text { Transcervical ( }( \pm \\
\text { transpartid) } \\
\text { approach }\end{array}$ \\
\hline Class III & $\begin{array}{l}\text { Tumors extending into the upper compartment of the parapharyngeal space } \\
+/ \text { - infratemporal fossa } \\
\text { Tumors with an angle of contact of } 180 \text { degrees with the wall of the intemal, } \\
\text { extemal or the common carotid }\end{array}$ & & Indicated & $\begin{array}{l}\text { Transcervical- } \\
\text { transmastoid } \\
\text { approach }\end{array}$ \\
\hline Class IV & $\begin{array}{l}\text { Tumors extending into the upper compartment of the parapharyngeal space } \\
\text { and infratemporal fossa } \\
\text { and involving the jugular bulb } \\
\text { Tumors with an angle of contact of }>90 \text { degrees with the wall of the intemal, } \\
\text { extemal or the common carotid }\end{array}$ & & Indicated & $\begin{array}{l}\text { Infatemporal Fossa } \\
\text { Approach type A }\end{array}$ \\
\hline
\end{tabular}

Figure 4 Modification of the Shamblin classification.

\section{Surgical planning and intra-arterial stenting of the carotid}

Surgery is the treatment of choice for all neck paragangliomas, and this is reinforced by the fact that $6-12.5 \%$ of them have a malignant potential (51). Surgical planning involves the evaluation of (i) tumor extent, (ii) neural involvement, and (iii) ICA involvement and possible infiltration. The extension of the tumor must be evaluated not only in the horizontal dimensions, but also along the vertical dimension. In our earlier report on PPS tumors, we proposed to divide this space into upper, middle, and lower compartments (52). Such division enables us to apply appropriate 
surgical approaches to tumors in the relevant compartments. While a trans-cervical approach (with or without a transparotid extension) may be enough to manage any extension of the tumor into the lower or middle PPS, this is not always adequate to manage tumors involving the upper PPS or the infratemporal fossa.

Involvement of the ICA is one of the crucial factors that determines the surgical strategy for CBPs. It is best to identify the danger to the ICA due to its relationship with the tumor and deal with it preoperatively. A significant proportion of the mortality in HN-PGL surgery, reported in earlier series, was due to injury or resection of the ICA (53). ICA manipulation can be extremely dangerous, as it can result in spasm, thrombosis, rupture, massive stroke, and even death $(54,55)$. The intraoperative risk of vascular injury is especially high in irradiated or previously operated cases. The application of intra-arterial stenting in the management of ICA has proven to be of enormous benefit to the patient, especially in the case of Shamblin classes II and III tumors and complex tumors (i.e., associated with other PGLs), and this merits to be part of the standard protocol of CBP management. The presence of the stent greatly facilitates dissection and mobilization of the ICA (Figure 5). The greatest risk is a potential injury at the transition point of the stented and non-stented artery, and

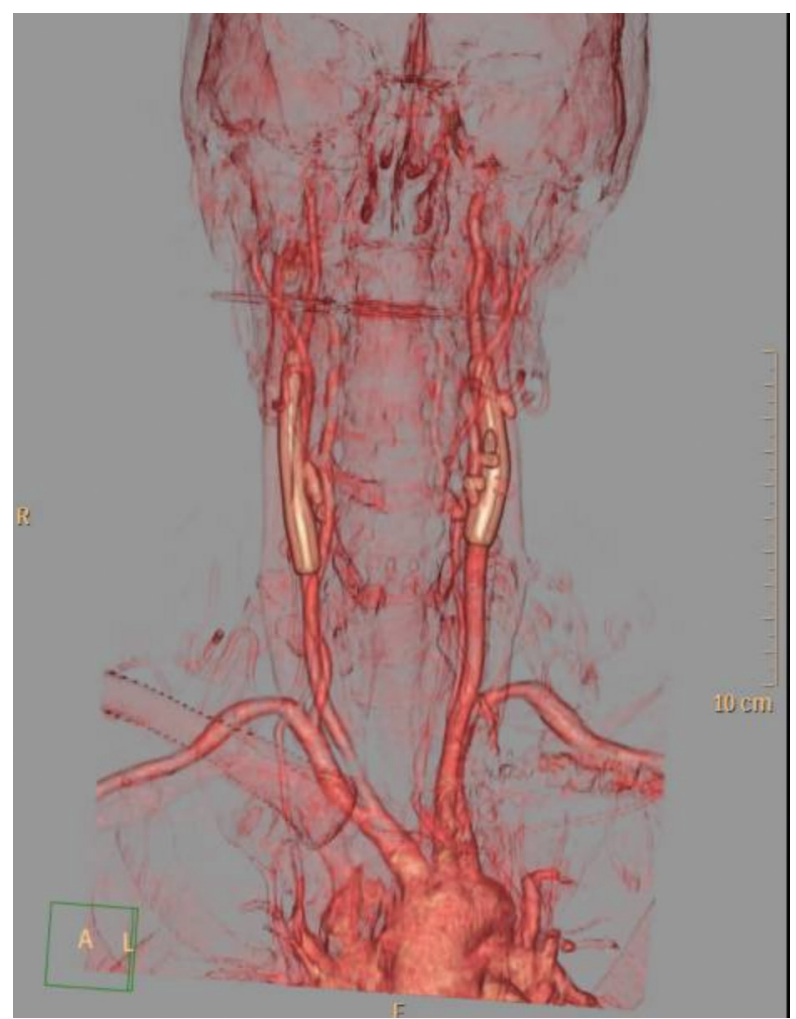

Figure 5 Digital subtraction angiography showing intra-arterial stenting in a case of CBT. 
minimization of traction is essential at this point. To reduce this particular risk, we ensure that the stent covers the ICA $1 \mathrm{~cm}$ proximal and distal to the tumor. Potential complications associated with lifelong antiplatelet therapy (i.e., gastrointestinal ulcers and mucosal bleeding) are the main drawbacks associated with ICA reinforcement with stent. However, the risk is diminished with the low dose of aspirin generally prescribed.

The following surgical approaches are used based on the compartmentalization of the PPS into upper, middle, and lower PPS:

- Transcervical approach (TCA) for tumors of the lower PPS-In this approach, the posterior belly of the digastric muscle is resected, the extra-temporal facial nerve (FN) is identified, and the styloid process is transected to allow larger and safer access to the PPS (Figure 6).

- Transcervical-transparotid approach (TC-TPA) for tumors of the middle PPS-In addition to the TCA, this procedure includes parotidectomy with preservation of the FN.

- Transcervical-transmastoid approach (TC-TMA) for tumors of the upper PPS with a posterior extension-In this approach, the TCA is extended to the postauricular region, with a view to open the lateral skull base. In this procedure, the mastoid tip is removed, leaving the VII nerve in its canal. This is followed by infralabyrinthine dissection to expose the sigmoid sinus and the jugular bulb in order to control the uppermost part of the tumor.

- Infratemporal fossa approach-type A (ITFA-A) for tumors of the upper PPS with extension to the vertical tract of the ICA and the jugular bulb-In this approach, a permanent anterior transposition of the facial nerve is performed to provide optimal exposure of the uppermost parapharyngeal ICA, the vertical portions of the petrous ICA and the jugular foramen.

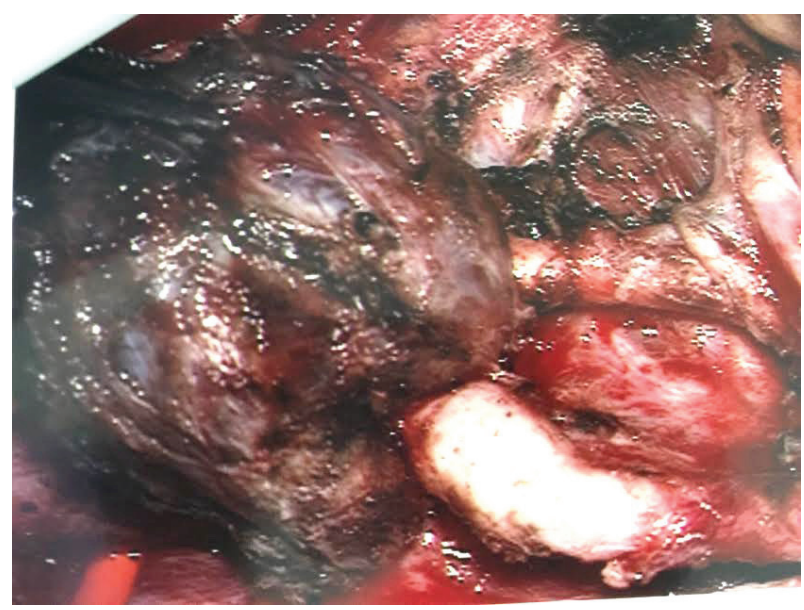

Figure 6 Intraoperative view of a massive CBP being separated from the ICA. 


\section{CONCLUSION}

CBPs and VPs are frequently associated with genetic predisposition, particularly with mutations regarding SDH genes. As in the case of other PGLs, genetic counseling is recommended since they can occur in familial forms and can have bilateral or multicentric presentations. CBPs are most frequent in populations living at high altitudes. The microscopic morphology of CBPs and VPs is comparable to that of other HN-PGLs. Overall, they are challenging lesions to treat and no drug therapies are currently available; however, since they are mostly non-metastatic, surgical success rates are high if the preoperative assessment is undertaken carefully. Preoperative endovascular intervention in the form of intra-arterial stents in the cervical and petrous segments of the ICA has transformed the therapeutic management of CBPs. Stenting of the ICA gives a chance for complete tumor removal with arterial preservation. It reduces the risk of injury to the artery during surgery and also eliminates the need of potentially troublesome maneuvers like permanent balloon occlusion, bypass procedures, and arterial repair or reconstruction in case of a damage. TCA is the ideal approach for tumors of the lower compartment of PPS, TCA/TC-TPA is the ideal approach for the middle compartment, and TC-TMA or the ITFA type A are the ideal approaches for the upper compartment. The use of an operating microscope combined with bipolar cautery during surgeries leads to improved results and decreases postoperative complications.

Acknowledgments: This work was supported by the Italian Association for Cancer Research (AIRC), grants IG9168 (2009-2012) and IG16932 (2015-2017) to RMC. We gratefully acknowledge the services provided by the Mario Sanna Foundation Onlus, Piacenza, Italy, dedicated to the prevention and treatment of skull base tumors. We thank Ms Anna Nassani, Department of Anatomic Pathology, Guglielmo da Saliceto Hospital, for her kind and expert help with immunohistochemistry.

Conflict of interest: The authors declare no conflicts of interest with respect to research, authorship, and/or publication of this book chapter.

Copyright and permission statement: We confirm that the materials included in this chapter do not violate copyright laws. Where relevant, appropriate permissions have been obtained from the original copyright holder(s). All original sources have been appropriately acknowledged and/or referenced.

\section{REFERENCES}

1. Gonzalez-Orus Alvarez-Morujo RJ, Aristegui Ruiz MA, da Costa Belisario J, Martinez Guirado T, Scola Yurrita B. Head and neck paragangliomas: Experience in 126 patients with 162 tumours. Acta Otorrinolaringol Esp. 2015;66:332-41. http://dx.doi.org/10.1016/j.otoeng.2014.11.004

2. Taieb D, Kaliski A, Boedeker CC, Martucci V, Fojo T, Adler JR, Pacak K. Current approaches and recent developments in the management of head and neck paragangliomas. Endocrine Rev. 2014;35:795-819. http://dx.doi.org/10.1210/er.2014-1026 
3. Netterville JL, Jackson CG, Miller FR, Wanamaker JR, Glasscock ME. Vagal paraganglioma: A review of 46 patients treated during a 20-year period. Arch Otolaryngol Head Neck Surg. 1998;124(10):1133-40. http://dx.doi.org/10.1001/archotol.124.10.1133

4. Rodríguez-Cuevas S, López-Garza J, Labastida-Almendaro S. Carotid body tumors in inhabitants of altitudes higher than 2000 meters above sea level. Head Neck. 1998 Aug;20(5):374-8. http://dx.doi. org/10.1002/(SICI)1097-0347(199808)20:5\%3C374::AID-HED3\%3E3.0.CO;2-V

5. Astrom K, Cohen JE, Willett-Brozick J, Aston CE, Baysal BE. Altitude is a phenotypic modifier in hereditary paraganglioma type 1: Evidence for an oxygen-sensing defect. Hum Genet. 2003 Aug;113(3):228-37. http://dx.doi.org/10.1007/s00439-003-0969-6

6. Sajid MS, Hamilton G, Baker DM, Joint Vascular Research Group. A multicenter review of carotid body tumour management. Eur J Vasc Endovasc Surg. 2007 Aug;34(2):127-30. http://dx.doi. org/10.1016/j.ejvs.2007.01.015

7. Lee JH, Barich F, Karnell LH, Robinson RA, Zhen WK, Gantz BJ, et al. National cancer data base report on malignant paragangliomas of the head and neck. Cancer. 2002;94:730-7. http://dx.doi. org/10.1002/cncr.10252

8. Davila VJ, Chang JM, Stone WM, Fowl RJ, Bower TC, Hinni ML, et al. Current surgical management of carotid body tumors. J Vasc Surg. 2016;64:1703-10. http://dx.doi.org/10.1016/j.jvs.2016.05.076

9. Dahia PL. Pheochromocytoma and paraganglioma pathogenesis: Learning from genetic heterogeneity. Nat Rev Cancer. 2014;14:108-19. http://dx.doi.org/10.1038/nrc3648

10. Williams MD. Paragangliomas of the head and neck: An overview from diagnosis to genetics. Head Neck Pathol. 2017;11:278-87. http://dx.doi.org/10.1007/s12105-017-0803-4

11. Pacak K, Wimalawansa SJ. Pheochromocytoma and paraganglioma. Endocr Pract. 2015;21:406-12. http://dx.doi.org/10.4158/EP14481.RA

12. Benn DE, Robinson BG, Clifton-Bligh RJ. 15 years of paraganglioma: Clinical manifestations of paraganglioma syndromes types 1-5. Endocr Relat Cancer. 2015;22:T91-103. http://dx.doi.org/10.1530/ ERC-15-0268

13. Petr EJ, Else T. Genetic predisposition to endocrine tumors: Diagnosis, surveillance and challenges in care. Semin Oncol. 2016;43(5):582-90. http://dx.doi.org/10.1053/j.seminoncol.2016.08.007

14. Benn DE, Zhu Y, Andrews KA, Wilding M, Duncan EL, Dwight T, et al. Bayesian approach to determining penetrance of pathogenic SDH variants. J Med Genet. 2018;55:729-34. http://dx.doi. org/10.1136/jmedgenet-2018-105427

15. Piruat JI, Millán-Uclés Á. Genetically modeled mice with mutations in mitochondrial metabolic enzymes for the study of cancer. Front Oncol. 2014;4:200. http://dx.doi.org/10.3389/ fonc. 2014.00200

16. Snezhkina AV, Lukyanova EN, Kalinin DV, Pokrovsky AV, Dmitriev AA, Koroban NV, et al. Exome analysis of carotid body tumor. BMC Med Genomics. 2018;11(Suppl 1):17. http://dx.doi.org/10.1186/ s12920-018-0327-0

17. Barnes L, Tse LLY, Hunt JL. Carotid body paraganglioma. In: Barnes L, Eveson JW, Reichart P, Sidransky D, editors. Pathology and genetics of head and neck tumours. Lyon, France: IARC Press; 2005. p. 362-3.

18. Her YF, Nelson-Holte M, Maher LJ 3rd. Oxygen concentration controls epigenetic effects in models of familial paraganglioma. Clin Cancer Res. 2010 Aug 15;16(16):4148-54.

19. Cerecer-Gil NY, Figuera LE, Llamas FJ, Lara M, Escamilla JG, Ramos R, et al. Mutation of SDHB is a cause of hypoxia-related high-altitude paraganglioma. Clin Cancer Res. 2010;16:4148-54. http:// dx.doi.org/10.1158/1078-0432.CCR-10-0637

20. Chan JKC, Kimura N, Capella C, Gill A, Komminoth P, Lam AKY, et al. Paraganglion tumours. In: El-Nigger AK, Chan JKC, Grandis JF, Takata T, Slootweg PJ, editors. WHO classification of head and neck tumours. 4th ed. Lyon: IARC; 2017. p. 275-84.

21. Lack EE. Tumors of the adrenal glands and extraadrenal paraganglia. AFIP atlas of tumor pathology, Series 4, Fasc. 8. Washington, DC: American Registry of Pathology and Armed forces Institute of Pathology; 2007. 500 p. Head \& Neck chap 12 323-9, Carotid chap 13 331-54, Vagal chap 15: 379-92.

22. Lam AK. Update on adrenal tumors in 2017 World Health Organization (WHO) of endocrine tumours. Endocr Pathol. 2017 Sept;28(3):213-27. http://dx.doi.org/10.1007/s12022-017-9484-5 
23. Piccini V, Rapizzi E, Bacca A, Di Trapani G, Pulli R, Giachè V, et al. Head and neck paragangliomas: Genetic spectrum and clinical variability in 79 consecutive patients. Endocr Relat Cancer. 2012;19(2):149-55. http://dx.doi.org/10.1530/ERC-11-0369

24. Shamblin WR, ReMine WH, Sheps SG, Harrison EG Jr. Carotid body tumor (chemodectoma). Clinicopathologic analysis of ninety cases. Am J Surg. 1971;122:732-9. https://doi.org/10.1016/ 0002-9610(71)90436-3

25. Nora JD, Hallett JW Jr, O'Brien PC, Naessens JM, Cherry KJ Jr, Pairolero PC. Surgical resection of carotid body tumors: Long-term survival, recurrence, and metastasis. Mayo Clin Proc. 1988;63:348-52. http://dx.doi.org/10.1016/S0025-6196(12)64856-3

26. Heinrich MC, Harris AE, Bell WR. Metastatic intravagal paraganglioma. Case report and review of the literature. Am J Med. 1985;78:1017-24. http://dx.doi.org/10.1016/0002-9343(85)90226-8

27. Turchini J, Cheung VKY, Tischler AS, De Krijger RR, Gill AJ. Pathology and genetics of phaeochromocytoma and paraganglioma. Histopathology. 2018 Jan;72:97-105. http://dx.doi.org/10.1111/ his. 13402

28. Offergeld C, Brase C, Yaremchuk S, Mader I, Rischke HC, Gla"sker S, et al. Head and neck paragangliomas: Clinical and molecular genetic classification. Clinics. 2012;67(S1):19-28. http://dx.doi. org/10.6061/clinics/2012(Sup01)05

29. Boedeker CC, Neumann HPH, Maier W, Bausch B, Jörg Schipper J, Ridder GJ. Malignant head and neck paragangliomas in SDHB mutation carriers. Otolaryngol Head Neck Surg. 2007;137:126-9. http://dx.doi.org/10.1016/j.otohns.2007.01.015

30. Rijken JA, Niemeijer ND, Leemans CR, Eijkelenkamp K, van der Horst-Schrivers ANA, van Berkel A, et al. Nationwide study of patients with head and neck paragangliomas carrying SDHB germline mutations. BJS Open. 2018;2:62-9. http://dx.doi.org/10.1002/bjs5.39

31. Gimenez-Roqueplo AP, Favier J, Rustin P, Rieubland C, Crespin M, Nau V, et al. Mutations in the SDHB gene are associated with extra-adrenal and/or malignant phaeochromocytomas. Cancer Res. 2003;63:5615-21.

32. Van Nederveen FH, Gaal J, Favier J, Korpershoek E, Oldenburg RA, de Bruyn EMCA, et al. An immunohistochemical procedure to detect patients with paraganglioma and phaeochromocytoma with germline SDHB, SDHC, or SDHD gene mutations: A retrospective and prospective analysis. Lancet Oncol. 2009;10(8):764-71. http://dx.doi.org/10.1016/S1470-2045(09)70164-0

33. Papathomas TG, Oudijk L, Persu A, Gill A, van Nederveen F, Tischler A, et al. SDHB/SDHA immunohistochemistry in pheochromocytomas and paragangliomas: A multicenter interobserver variation analysis using virtual microscopy: A Multinational Study of the European Network for the Study of Adrenal Tumors (ENS@T). Mod Pathol. 2015;28(6):807-21. http://dx.doi.org/10.1038/ modpathol.2015.41

34. Gill AJ, Benn DE, Chou A, Clarkson A, Muljono A, Meyer-Rochow GY, et al. Immunohistochemistry for SDHB triages genetic testing of SDHB, SDHC, and SDHD in paraganglioma-pheochromocytoma syndromes. Hum Pathol. 2010;41(6):805-14. http://dx.doi.org/10.1016/j.humpath.2009.12.005

35. Jansen TTG, Marres HAM, Kaanders J, Kunst HPM. A meta-analysis on the surgical management of paraganglioma of the carotid body per Shamblin class. Clin Otolaryngol. 2018. http://dx.doi. org/10.1111/coa.13116

36. Del Guercio L, Narese D, Ferrara D, Butrico L, Padricelli A, Porcellini M. Carotid and vagal body paragangliomas. Transl Med Unisa. 2013;6:11-15.

37. Pellitteri PK, Rinaldo A, Myssiorek D, Jacksond CG, Bradleye PJ, Devaney KO, et al. Paragangliomas of the head and neck. Oral Oncol. 2004;40:563-75. http://dx.doi.org/10.1016/j.oraloncology.2003.09.004

38. van der Mey AG, Jansen JC, van Baalen JM. Management of carotid body tumors. Otolaryngol Clin North Am. 2001;34:907-924, vi. http://dx.doi.org/10.1016/S0030-6665(05)70354-6

39. Suarez C, Rodrigo JP, Mendenhall WM, Hamoir M, Silver CE, Grégoire V, et al. Carotid body paragangliomas: A systematic study on management with surgery and radiotherapy. Eur Arch Otorhinolaryngol. 2014;271:23-34. http://dx.doi.org/10.1007/s00405-013-2384-5

40. Boscarino G, Parente E, Minelli F, Ferrante A, Snider F. An evaluation on management of carotid body tumour (CBT). A twelve years experience. G Chir. 2014;35:47-51. http://dx.doi.org/10.11138/ gchir/2014.35.1.047 
41. Badenhop RF, Jansen JC, Fagan PA, Lord RS, Wang ZG, Foster WJ, et al. The prevalence of SDHB, SDHC, and SDHD mutations in patients with head and neck paraganglioma and association of mutations with clinical features. J Med Genet. 2004;41:e99. http://dx.doi.org/10.1136/jmg.2003.011551

42. Zanoletti E, Mazzoni A. Vagal paraganglioma. Skull Base. 2006;16:161-7. http://dx.doi.org/10. 1055/s-2006-949519

43. Lozano Sanchez FS, Munoz Herrera A. [Surgical treatment of carotid paragangliomas]. Acta Otorrinolaringol Esp. 2009;60(Suppl 1):80-96.

44. Sniezek JC, Netterville JL, Sabri AN. Vagal paragangliomas. Otolaryngol Clin North Am. 2001;34: 925-39, vi. http://dx.doi.org/10.1016/S0030-6665(05)70355-8

45. Shamblin WR, ReMine WH, Sheps SG, Harrison EG Jr. Carotid body tumor (chemodectoma). Clinicopathologic analysis of ninety cases. Am J Surg. 1971;122:732-9. http://dx.doi. org/10.1016/0002-9610(71)90436-3

46. Luna-Ortiz K, Rascon-Ortiz M, Villavicencio-Valencia V, Granados-Garcia M, Herrera-Gomez A. Carotid body tumors: Review of a 20-year experience. Oral Oncol. 2005;41:56-61. http://dx.doi. org/10.1016/j.oraloncology.2004.06.006

47. Arya S, Rao V, Juvekar S, Dcruz AK. Carotid body tumors: Objective criteria to predict the Shamblin group on MR imaging. AJNR Am J Neuroradiol. 2008;29:1349-54. http://dx.doi.org/10.3174/ajnr. Al092

48. Suarez C, Rodrigo JP, Bodeker CC, Llorente JL, Silver CE, Jansen JC, et al. Jugular and vagal paragangliomas: Systematic study of management with surgery and radiotherapy. Head Neck. 2013;35:1195-204. http://dx.doi.org/10.1002/hed.22976

49. Alvarez-Morujo RJ, Ruiz MA, Serafini DP, Delgado IL, Friedlander E, Yurrita BS. Management of multicentric paragangliomas: Review of 24 patients with 60 tumors. Head Neck. 2016;38:267-76. http:// dx.doi.org/10.1002/hed.23894

50. Piazza P, Di Lella F, Bacciu A, Di Trapani G, Ait Mimoune H, Sanna M. Preoperative protective stenting of the internal carotid artery in the management of complex head and neck paragangliomas: Longterm results. Audiol Neurotol. 2013;18:345-52. http://dx.doi.org/10.1159/000354158

51. Zhang WC, Cheng JP, Li Q, Zhang L, Wang XD, Anniko M. Clinical and pathological analysis of malignant carotid body tumour: A report of nine cases. Acta Otolaryngol. 2009;129:1320-5. http:// dx.doi.org/10.3109/00016480802660510

52. Prasad SC, Piccirillo E, Chovanec M, La Melia C, De Donato G, Sanna M. Lateral skull base approaches in the management of benign parapharyngeal space tumors. Auris Nasus Larynx. 2015;42:189-98. http://dx.doi.org/10.1016/j.anl.2014.09.002

53. Sanna M, Flanagan S. Surgical management of lesions of the internal carotid artery using a modified Fisch Type A infratemporal approach. Otol Neurotol. 2007;28:994. http://dx.doi.org/10.1097/01. MAO.0000271715.92886.9e

54. Sanna M, Khrais T, Menozzi R, Piazza P. Surgical removal of jugular paragangliomas after stenting of the intratemporal internal carotid artery: A preliminary report. Laryngoscope. 2006;116:742-6. http://dx.doi.org/10.1097/01.mlg.0000205199.61105.cb

55. Jackson CG, McGrew BM, Forest JA, Netterville JL, Hampf CF, Glasscock ME 3rd. Lateral skull base surgery for glomus tumors: Long-term control. Otol Neurotol. 2001;22:377-82. http://dx.doi. org/10.1097/00129492-200105000-00018 